\title{
Knee osteoarthritis in women
}

\author{
Sharon L. Hame • Reginald A. Alexander
}

Published online: 8 March 2013

(C) Springer Science+Business Media New York 2013

\begin{abstract}
Osteoarthritis is a disease that progresses over time and culminates in the destruction of articular cartilage and joints. Thus, with an increasing elderly population the treatment of knee osteoarthritis has become a major healthcare issue. It has been shown that women are more severely impacted by knee osteoarthritis. Differences in knee anatomy, kinematics, previous knee injury, and hormonal influences may play a role. Sex difference with respect to osteoarthritis presentation, treatment, and the allocation of resources also exists. In general, women present for treatment in more advanced stages of osteoarthritis and have more debilitating pain than their male counterparts. In addition, healthcare providers are more likely to recommend total joint arthroplasty for their male patients. Understanding how and why these gender differences occur is instrumental in formulating an inclusive strategy for combating osteoarthritis in the future.
\end{abstract}

Keywords Women · Knee · Osteoarthritis · Gender .

Treatment $\cdot$ Total knee arthroplasty $\cdot$ Elderly

\section{Introduction}

Osteoarthritis of the knee is very common, affecting 12.4 million (33.6\%) adults over the age of 65 [1]. Interestingly, women are more affected and burdened by osteoarthritis of the knee than men [2-6]. Studies have shown that osteoarthritis is expressed differently in women than in men and may affect certain parts of the knee disproportionally $[4,7 \cdot, 8,9]$. This is particularly evident in the patellofemoral joint where isolated

S. L. Hame $(\bowtie) \cdot$ R. A. Alexander

Division of Sports Medicine, Department of Orthopaedic Surgery,

David Geffen School of Medicine at UCLA,

10833 Le Conte Ave. CHS 76-126,

Los Angeles, CA 90095, USA

e-mail: Shame@mednet.ucla.edu patellofemoral arthritis is more prevalent in women than in men $[4,10]$. In addition to the anatomic area affected, women usually present in more advanced stages compared with men, have different gait patterns [11], and report more pain and disability $[8,9,12,13]$. In a study about knee pain and disability in the community, McAlindon et al. found that the frequency of reported disability relating to knee arthritis was significantly higher in women than men [8].

Differences in the radiographic presentation of osteoarthritis have also been shown in large cohorts of patients. Felson et al. using the Framingham Heart Study cohort, demonstrated that radiographic evidence of osteoarthritis increased with age from $27 \%$ in subjects younger than 70 , to $44 \%$ in subjects age 80 or older. When considering gender, they found a slightly higher prevalence of radiographic osteoarthritis in women than in men (Fig. 1). Thus, they concluded that there were a significantly higher number of women with symptomatic disease [3].

\section{Causes of knee osteoarthritis in women}

The reasons for the differences in the presentation and development of osteoarthritis of the knee in women compared with men have not been well studied. Ultimately, the cause may be multifactorial and include anatomic differences, previous trauma, and genetic and hormonal issues. The anatomic differences between males and females that may play a role include narrower femurs, thinner patellae, larger quadriceps angles, and differences in tibial condylar size [14]. These differences have led to the development of gender-specific total knee replacements. Although these differences exist, there has been no link established between them and the development of osteoarthritis. Differences in knee cartilage volume, however, may play an important role. Using analysis of sequential magnetic resonance imaging (MRI), Hanna et al. observed that men had significantly 


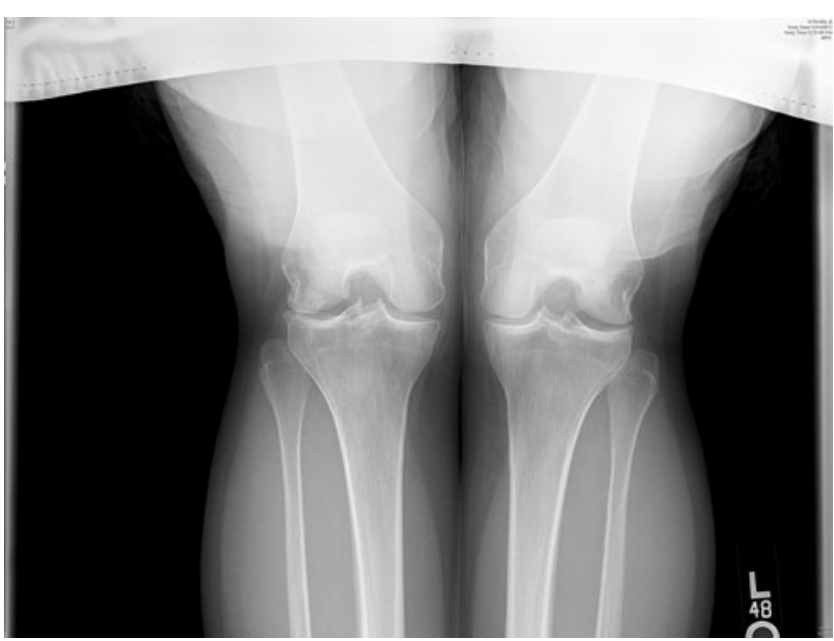

Fig. 1 Knee osteoarthritis in a 47-year-old female

greater total tibial and patella cartilage volume than women and that women had a significantly higher prevalence of patellar cartilage defects at baseline. Over time women showed more knee cartilage volume loss when compared with their male counterparts. As a result, women may have an increased risk of progression of tibiofemoral cartilage defects [7•]. Although not definitively proven, less baseline cartilage and increased volume loss are likely contributing factors to knee arthritis in women. Given the lack of evidence in this area, further studies on anatomic reasons for the development of osteoarthritis are clearly indicated.

In combination with anatomical differences, kinematic differences may also play a role in the development of osteoarthritis in women. Chapell et al. examined knee kinetic differences between men and women with regards to stop-jump tasks. Women demonstrated greater anterior and posterior shear forces, greater extension and valgus moments than men [15]. Other studies have shown similar differences between males and females [16-19]. Altered mechanics and increased valgus moments may put more abnormal stress on female athletes' knees leading to an increase in the risk of knee osteoarthritis.

Another important factor that may put women at risk for osteoarthritis of the knee is a history of knee injury. It has been well established that women have increased incidence of anterior cruciate ligament (ACL) injuries and that these injuries lead to future osteoarthritis regardless of gender [20, 21]. ACL injury often results in a characteristic bone bruise on both the lateral femoral condyle and lateral tibia plateau as demonstrated on MRI. In addition, the effects of a hemarthrosis and the release of factors and their effect on articular cartilage are unknown., It can be theorized that these traumatized articular surfaces whether from impact or from a toxic milieu may increase the risk of developing osteoarthritis. However, more studies with long -term follow up are needed to establish a definitive link. A recent study by $\mathrm{Chu}$ et al. demonstrated that randomized controlled trials for early arthritis interventions following acute ACL tear were possible through collaboration [22]. The results of these studies could greatly impact the health of women and their knees.

Hormonal differences between men and women may play a role in the development of osteoarthritis. Postmenopausal women, in particular, have an increased risk of developing arthritis and this has been linked to the decrease in estrogen during this time. Richmond et al. identified estrogen receptors in articular cartilage [23] and although the clinical significance of the receptors is not fully understood, their existence implies a potential relationship between estrogen and articular cartilage health. In a more clinically related study, Zhang et al. demonstrated that postmenopausal women who take estrogen replacement therapy have a decreased chance of developing radiographic evidence of knee arthritis. In addition, the protective effect of estrogen replacement therapy was increased with the duration of the therapy [24]. It appears that estrogen may have a beneficial effect on cartilage; however, the exact mechanism of this protection has yet to be elucidated. Other hormones and growth factors may also affect osteoarthritis in women. Richmond et al. using estrogen-treated surgically menopausal monkeys as models, observed an increase in proteoglycans and insulinlike growth factor binding protein-2 (IGFBP-2) in the cartilage treated with estrogen. IGFBP's have been shown to be produced by chondrocytes but little is known about their exact function in cartilage [23]. Others have shown decreased IGF-1 levels in women who underwent total knee replacement compared with male patients [25]. Future research on the effects and potential benefits of hormones and growth factors is needed to fully clarify their role in the development of knee osteoarthritis.

\section{Diagnosis}

The diagnosis of osteoarthritis of the knee does not differ between men and women. A history of knee pain, stiffness, crepitus, and swelling is common to both genders but a difference in the severity of symptoms does exist. Women typically present with worse symptoms including greater complaints of pain and disability $[8,26]$. More advanced radiographic findings are also common [10]. Radiographic evaluation should include weight-bearing views to determine the alignment of the limb. The amount of joint space narrowing, osteophyte formation, sclerosis, and subchondral cysts should be identified. Further imaging with magnetic resonance imaging is generally not required for moderate to advanced stages of arthritis unless other pathology is suspected. The reasons for gender-related differences in presentation can only be speculated at this time and further 
research is needed in order to implement appropriate treatment options.

\section{Treatment}

Recommendations for the treatment of osteoarthritis of the knee range from activity modification and anti-inflammatory medication to total knee arthroplasty, depending on the disability of the patient and the severity of the disease. Although likely to have existed for some time, only recently have differences in recommendations and treatment based on gender been reported [1, 12, 27-29].

The non-operative management of osteoarthritis is multimodal, and may include exercise, bracing, non-steroidal anti-inflammatory medication, corticosteroid injections, viscosupplementation injections, and complementary and alternative medicine. Exercise can reduce pain and increase function in a patient with early arthritic changes [30]. Some evidence supports the recommendation that a low impact weight-bearing program may be beneficial to patients with osteoarthritis [31]. However, the effects of exercise programs may be lost after 6 months if patients do not maintain the exercise program [31, 32]. The American Academy of Orthopaedic Surgeons (AAOS) also recommends weight loss in addition to activity modification as a means to reduce symptoms. Gender differences with respect to exercise, activity modification and weight loss on the symptoms and progression of knee arthritis have not been fully studied to date.

The use of a knee brace is quite common in the treatment of knee osteoarthritis and can include knee sleeves, hinged knee braces, and custom knee unloading braces. Braces are designed to reduce swelling, improve stability, and, in the case of the unloader brace, reduce mechanical load in the diseased compartment of the knee [30]. Very little data exists regarding the effectiveness of bracing in the treatment of osteoarthritis. The anatomic differences and kinematic differences between the female and male knee suggest that females may respond to bracing differently than males. Gender-specific bracing has been designed by some companies, however, there is no evidence to show that these braces are more effective in females in reducing symptoms and improving function. Currently, the recommendation for the use of a brace in the treatment of osteoarthritis is a decision made between the patient and the physician and should be based on clinical symptoms, radiographic findings, and the patient's ability to be compliant with a brace.

Nonsteroidal anti-inflammatory drugs, or NSAIDs, are a common adjunct in the symptomatic management of osteoarthritis of the knee. Their use should be limited in older patients, male or female. Patients with bleeding disorders; gastrointestinal, cardiovascular, or renal disease, and anticoagulation use are at increased risk for adverse effects.
Gender differences in the type of NSAID used and the dosing has not been adequately studied and, therefore, recommendations for women with osteoarthritis have remained the same as men. Future research may identify more effective drugs and drug regimens for women with knee osteoarthritis. Currently, recommendations for NSAID use should be determined by the physician on a case-by-case basis

In addition to NSAIDs, intra-articular corticosteroid injections have been a staple of symptomatic management of osteoarthritis. These injections can be helpful in combating painful flair ups but require invasive techniques, which can lead to complications, including infection. Difficulties in accuracy with intra-articular injections have been reported $[33,34]$. Corticosteroid injections in combination with local anesthetics are common and recent evidence suggests that these medications, though they relieve pain, may have chondrodestructive properties $[35,36]$.

Increasingly more attention is being paid to viscosupplementation for the treatment of knee arthritis. The use of hyaluronic acid (HA) injections has theoretic benefits that may combat arthritis. Hyaluronic acid has viscoelastic properties and chondroprotective potential [30,37]; however, its theoretic benefits have yet to translate into evidence of dramatic clinical improvement. To date, viscosupplemenation has only been shown to be somewhat efficacious in the short-term relief of the symptomatic knee with early arthritis $[30,37]$. No studies have reported gender differences with respect to corticosteroid use or viscosupplementation. More randomized control trials are needed to determine if these treatment options are appropriate for patients, male and female, with all degrees of arthritis of the knee

Complementary and alternative medicine (CAM) has been used in the treatment of osteoarthritis of the knee for many years. Treatments in this category include herbal remedies, acupuncture, mind-body intervention (ie, yoga, Tai Chi, etc.), spiritual activities, topical therapies, and oral supplements including glucosamine and chondroitin sulfate. Jawahar et al. studied the effects of gender and the use of alternative medicine in a large cohort of patients with radiographically confirmed knee osteoarthritis [38•]. In the study they found equal use of glucosamine and chondroitin sulfate therapies between genders. However, women were more likely to use mind-body interventions, acetaminophen, NSAIDs, and topical agents [38•]. Ultimately, the study supported the conclusion that women are more likely than men to use complementary and alternative medicine alone or in combination with conventional medical modalities for the treatment of knee osteoarthritis [38•].

The role of arthroscopy in the treatment of knee osteoarthritis has been controversial. It is widely practiced but the clinical data supporting its use has been lacking. Kirkley et al. compared medical management combined with physical therapy, to medical management with physical therapy and 
arthroscopic debridement. From this study they concluded that there is no benefit, in terms of outcome scores, between medical management with physical therapy and arthroscopic debridement [39]. Currently the AAOS guidelines suggest a limited role for arthroscopic debridement of symptomatic meniscal tears and/or loose bodies, as long as signs and symptoms correlate with the pathology [31].

For those patients who have end-stage arthritis and debilitating symptoms, total knee arthroplasty remains the gold standard for pain relief. Demand for this procedure is expected to increase with the increasing age of the population and is expected to reach 1.5 million procedures in 2020 [40]. Since osteoarthritis is more common in women it is understandable that women undergo more total knee arthroplasties than men. However, it has been shown that women underutilize total knee arthroplasty, more than men $[41,42 \bullet \bullet$. Women have also demonstrated lower functional scores before surgery $[43,44]$ and more advanced disease at the time of surgery [45]. Lower functional scores may result from more advanced disease, increased pain and muscle atrophy, and impaired quadriceps function.

Despite the increased burden of osteoarthritis in women, disparities continue to exist. The idea of gender difference in healthcare and disease treatment and prevention is not new. Women are less likely to receive dialysis, or undergo cardiac catheterization, or renal transplant compared with male counter parts [46]. Likewise, there are also disparities in the management of arthritis. Even though women have a higher prevalence of osteoarthritis in the knee, with worse symptoms, and more disability, they are less likely to undergo total knee arthroplasty.

Unconscious bias on the part of the physician has been shown to play a role in the recommendation for total knee arthroplasty. Borkhoff et al. presented standardized male and female patients with moderate arthritis to both family physicians and orthopedic surgeons for recommendations regarding whether or not the patient needed joint replacement. In this study $42 \%$ of physicians suggested total knee arthroplasty to their male patients but not female patients. Eight percent of physicians suggested total knee arthroplasty for female patients but not male patients [1]. When separated into physician type, the odds of an orthopedic surgeon recommending total knee arthroplasty to a male patient was 22 times that of the female patient $[1,12,46]$. To improve the equality and care of the female patient with osteoarthritis of the knee, physicians need to be aware of their subconscious bias with regards to the treatment of knee osteoarthritis in men and women.

The reasons for bias in the recommendation for total knee arthroplasty in women is likely multifactorial. First, there may be a perception that women's symptoms are an exaggeration. Some physicians may attribute part of their patients' complaints to being "emotional" or overly dramatic [1]. Second, physicians may believe that their female patients do not do as well functionally with surgery as their male counterparts $[9,41]$. Studies have shown women do have the same amount of functional gains postoperatively as men; however, they are starting with more disability preoperatively [9, 46-48]. Third, it is a popular belief that women have more complications postoperatively than men. However, it has been shown that men have a higher risk of revision surgery $[42 \bullet \bullet]$.

The female patient and her perception of surgery, disability, and outcome may also contribute to the disparity of total knee arthroplasty in women. Women's perception of the benefits of surgery, lack of personal experience with surger$\mathrm{y}$, and trust in the outcome may play a role in seeking care $[29,42 \bullet \cdot$. Women have been also shown to be more concern than men about anesthesia, pain, and recovery [42••, $48,49]$. In addition, women may be more willing to forgo surgery and accept disability and less willing to accept the risks of surgery and any disruption in their care giving responsibilities $[42 \bullet \bullet, 50]$.

\section{Future directions}

Future goals should include more high quality studies that are sufficiently powered to examine gender differences in knee osteoarthritis. Despite being a majority of the population, women's representation in scientific research on women still lags behind that of men's [42••, 51, 52]. The reasons for this are varied: inequality in recruitment, women excluded because of pregnancy, and willingness to participate. Ramasubbu et al. reported only $24.6 \%$ of clinical trials participants in studies published in the New England Journal of Medicine were women [51]. In addition, gender-specific analysis was available in only $14 \%$ of the aforementioned trials [51]. Ultimately, drugs and devices approved for the entire population may have no effect, and even a detrimental effect, on the female population. In 2005, research showed that $80 \%$ of drugs taken off the market were due to side effects that affected women, not studied in initial drug trials [42••, 52]. Future studies should include gender evaluation to help prevent adverse reactions and recalls of drugs and devices that may affect males and females differently.

\section{Conclusion}

Knee osteoarthritis is an important topic because it affects the quality of life of millions of people. How osteoarthritis is manifested and its impact on patients is varied. Women typically present with more advanced stages and more disability than men. The reasons for this are multifactorial but may be related to less cartilage volume and greater cartilage wear, overall differences in mechanical alignment, and other 
gender and social factors. Likewise, the treatment of osteoarthritis is varied. Women tend to seek out and utilized more strategies that incorporate mind and body. However, despite starting with more preoperative pain and disability, women benefit from total joint arthroplasty as much as their male counterparts. Educating physicians and patients on the benefits of treatment options, including arthroplasty, is the key to unlocking the issues of disparity in care in the treatment of knee osteoarthritis in women.

Conflicts of interest Sharon L. Hame declares that she has no conflict of interest. Reginald A. Alexander declares that he has no conflict of interest

\section{References}

Papers of particular interest, published recently, have been highlighted as:

- Of importance

-. Of major importance

1. Borkhoff CM, Hawker GA, Kreder HJ, Glazier RH, Mahomed NN, Wright JG. The effect of patient's sex on physician's recommendations for total knee arthroplasty. CMAJ. 2008;178:681-7.

2. Blagojevic M, Jinks C, Jeffery A, Jordan KP. Risk factors for onset of osteoarthritis of the knee in elderly adults: a systematic review and meta-analysis. Osteoarthr Cartil. 2010;18:24-33.

3. Felson DT, Naimark A, Anderson J, Kazis L, Castelli W, Meenan RF. The prevalence of knee osteoarthritis in the elderly. The Framingham Osteoarthritis Study. Arthritis Rheum. 1987;30:914-8.

4. Felson DT, Zhang Y, Hannan MT, Naimack A, Weissman BN, Aliabadi $\mathrm{P}$, et al. The incidence and natural history of knee osteoarthritis in the elderly. The Framingham Osteoarthritis Study. Arthritis Rheum. 1995;38:1500-5.

5. O'Connor MI. Osteoarthritis of the hip and knee: sex and gender differences. Orthop Clin N Am. 2006;37:559-68.

6. Srikanth VK, Fryer B, Math JL, Zhai G, Winzenberg TM, Hosmer $\mathrm{D}$, et al. A meta-analysis of sex differences prevalence, incidence, and severity of osteoarthritis. Osteoarthr Cartil. 2005;13:769-81.

7. - Hanna FS, Teichtahl AJ, Wluka AE, Wang Y, Urquhart DM, English DR, et al. Women have increased rates of cartilage loss and progression of cartilage defects at the knee than men: a gender study of adults without clinical knee osteoarthritis. Menopause. 2009;4:666-70. In this study MRI imaging is used to assess and compare the difference in articular cartilage volume loss between men and women. Women demonstrated a greater overall average cartilage volume loss compared with men.

8. McAlindon TE, Cooper C, Kirwan JR, Dieppe PA. Knee pain and disability in the community. Br J Rheumatol. 1992;31:189-92.

9. O'Connor MI. Sex differences in osteoarthritis of the hip and knee. J Am Acad Orthop Surg. 2007;15:S23-5.

10. McAlindon TE, Snow S, Cooper C, Dieppe PA. Radiographic patterns of osteoarthritis of the knee joint in the community: the importance of the patellofemoral joint. Ann Rheum Dis. 1992;51:844-9.

11. Debi R, Mor A, Segal O, Segal G, Debbi E, Agar G, et al. Differences in gait patterns, function, and quality of life between males and females with knee osteoarthritis: a clinical trial. BMC Musculoskelet Disord. 2009;10:127-37.

12. O'Connor MI, Hooten EG. Gender disparities in knee osteoarthritis and TKA. Clin Orthop Relat Res. 2011;469:1883-5.

13. Thomas SG, Pagura SM, Kenney D. Physical activity and its relationship to physical performance in patients with end stage knee osteoarthritis. J Orthop Sports Phys Ther. 2003;12:745-54.

14. Conley S, Rosenberg A, Crowninshield R. The female knee: anatomic variations. J Am Acad Orthop Surg. 2007;15:S31-6.

15. Chapell JD, Yu B, Kirkendall DT, Garret WE. A comparison of knee kinetics between male and female recreational athletes in stop-jump tasks. Am J Sports Med. 2002;30:261-7.

16. Ford KR, Myer GD, Hewett TE. Valgus knee motion during landing in high school female and male basketball players. Med Sci Sports Exerc. 2003;35:1745-50.

17. Ford KR, Myer GD, Toms HE, Hewett TE. Gender differences in kinematics of unanticipated cutting in young athletes. Med Sci Sports Exerc. 2005;37:124-9.

18. Kernozek TW, Torry MR, Van Hoof H, Cowley H, Tanner S. Gender differences in frontal and sagittal plane biomechanics during drop landings. Med Sci Sports Exerc. 2005;37:1003-12.

19. Mendiquichia J, Ford KR, Quatman CE, Alentorn-Geil E, Hewett TE. Sex differences in proximal control of the knee joint. Sports Med. 2011;41:541-57.

20. Friel NA, Chu CR. The role of ACL injury in the development of posttraumatic knee osteoarthritis. Clin Sports Med. 2013;32:1-12.

21. Nelson F, Billinghurst RC, Pidoux I, Reiner A, Langworthy M, McDermott M, et al. Early post-traumatic osteoarthritis-like changes in human articular cartilage following rupture of the anterior cruciate ligament. Osteoarthr Cartil. 2006;2:114-9.

22. Chu CR, Beynnon BD, Dragoo JL, Fleisig GS, Hart JM, Khazzam $\mathrm{M}$, et al. The EARTH group: the feasibility of randomized controlled trials for early arthritis therapies (EARTH) involving acute anterior cruciate ligament tear cohorts. Am J Sports Med. 2012;40:2648-52.

23. Richmond RS, Carlson CS, Register TC, Shanker G, Loeser RF. Functional estrogen receptors in adult articular cartilage: estrogen replacement therapy increases chondrocyte synthesis of proteoglycans and insulin-like growth factor binding protein 2. Arthritis Rheum. 2000;43:2081-90.

24. Zhang Y, McAlindon TE, Hannan MT, Chaisson CE, Klein R, Wilson PW, et al. Estrogen replacement therapy and worsening of radiographic knee osteoarthritis: the Framingham study. Arthritis Rheum. 1998;41:1867-73.

25. Pagura SM, Thomas SG, Woodhouse LJ, Ezzat S. Women awaiting knee replacement have reduced function and growth hormone. Clin Orthop Relat Res. 2003;415:202-13.

26. Cho HJ, Chang CB, Yoo JH, Kim SJ, Kim TK. Gender difference in the correlation between symptom and radiographic severity in patients with knee osteoarthritis. Clin Orthop Relat Res. 2010;468:1749-58.

27. Katz JN, Wright EA, Guadagnoli E, Liang MH, Karlson EW, Cleary PD. Differences between men and women undergoing major orthopedic surgery for degenerative arthritis. Arthritis Rheum. 1994;37(5):687-94.

28. MacDonald SJ, Charron KD, Bourne RB, Naudie DD, McCalden $\mathrm{RW}$, Rorabeck CH. Gender - specific total knee replacement: prospectively collected clinical outcomes. Clin Orthop Relat Res. 2008;466:2612-6.

29. Suarez-Almazor ME, Souchek J, Kelly PA, O’Malley K, Byrne M, Richardson M, et al. Ethnic variation in knee replacement: patient preferences or uniformed disparity? Arch Intern Med. 2005;165:111724.

30. Feeley BT, Gallo RA, Sherman S, Williams RJ. Management of osteoarthritis of the knee in the active patient. J Am Acad Orthop Surg. 2010;18:407-16. 
31. Richmond J, Hunter D, Irrgang J, Jones MH, Levy B, Marx R, et al. Treatment of osteoarthritis of the knee (nonarthoplasty). J Am Acad Orthop Surg. 2009;17:591-600.

32. van Baar ME, Dekker J, Oostendorp RA, Bijl D, Voorn TB, Billsma JW. Effectiveness of exercise in patients with osteoarthritis of hip or knee: 9 months follow up. Ann Rheum Dis. 2001;60:1123-30.

33. Jackson DW, Evans NA, Thomas BM. Accuracy of needle placement into the intra-articular space of the knee. J Bone Joint Surg Am. 2001;84-A:1522-7.

34. McGary JG, Daruwalla ZJ. The efficacy, accuracy, and complications of corticosteroid injections of the knee joint. Knee Surg Sports Traumatol Arthrosc. 2011;19:1649-54.

35. Dragoo JL, Braun HJ, Kim HJ, Pham HD, Golish SR. The in vitro chondrotoxicity of single-dose local anesthetics. Am J Sports Med. 2012;4:794-9.

36. Dragoo JL, Korotkova T, Kim HJ, Jaqadish A. Chondrotoxicity of low $\mathrm{pH}$, epinephrine, and preservatives found in local anesthetics containing epinephrine. Am J Sports Med. 2010;6:1154-9.

37. Watterson JR, Esdaile JM. Viscosupplementation: therapeutic mechanisms and clinical potential in osteoarthritis of the knee. J Am Acad Orthop Surg. 2000;8:277-84.

38. - Jawahar R, Yang S, Eaton CB, McAlindon T, Lapane K. Genderspecific correlates of complementary and alternative medicine use for knee osteoarthritis. J Womens Health. 2012;21:1091-9. In this study the usage of CAM modalities are examined and compared between genders. Women were more likely than men to use CAM alone or in conjunction with conventional medications.

39. Kirkley A, Birmingham TB, Litchfield RB, Giffin JR, Willits KR, Wong CJ, et al. A randomized trial of arthroscopic surgery for osteoarthritis of the knee. N Engl J Med. 2008;359:1097-107.

40. Kurtz S, Ong K, Lau E, Ong K, Zhao K, Kelly M, et al. Projections of primary and revision hip and knee arthroplasty in the United States from 2005 to 2030. J Bone Joint Surg. 2007;4:780-5.

41. Hawker GA, Wright JG, Coyte PC, Williams JI, Harvey B, Glazer $\mathrm{R}$, et al. Differences between men and women in the rate of use of hip and knee arthroplasty. N Engl J Med. 2000;342:1016-22.
42. •• Novicoff WM, Saleh KJ. Examining sex and gender disparities in total joint arthroplasty. Clin Orthop Relat Res. 2011;469:1824 8. In this study the utilization of total joint arthroplasty and the potential causes of disparities and between genders are examined and explained. Differences in physician related and patient related issues are discussed.

43. O'Connor MI. Implant survival, knee function, and pain relief after TKA: are there differences between men and women? Clin Orthop Relat Res. 2011;469:1846-51.

44. Ritter MA, Wing JT, Berend ME, Davis KE, Meding JB. The clinical effect of gender on outcome of total knee arthroplasty. J Arthroplasty. 2008;23:331-6.

45. Petterson SC, Raisis L, Bodenstab A, Snyder-Makler L. Diseasespecific gender differences among total knee arthroplasty candidates. J Bone Joint Surg Am. 2007;89:2327-33.

46. Boyan BD, Tosi L, Coutts R, et al. On the horizon from the ORS. J Am Acad Orthop Surg. 2012;20:668-9.

47. Dalury DF, Mason JB, Murphy JA, Adams MJ. Analysis of the outcome in male and female patients using a unisex total knee replacement system. J Bone Joint Surg Br. 2009;91:35760.

48. Fortin PR, Clarke AE, Joseph L, Liang MH, Tanzer M, Ferland D, et al. Outcomes of total hip and knee replacement: preoperative functional status predicts outcome at 6 months after surgery. Arthritis Rheum. 1999;42:1722-8.

49. Chang HJ, Mehta PS, Rosenberg A, Scrimshaw SC. Concerns of patients actively contemplating total knee replacement: differences by race and gender. Arthritis Rheum. 2004;51:117-23.

50. Karlson EW, Daltroy LH, Liang MH, Eaton HE, Katz JN. Gender differences in patient preferences may underlie differential utilization of elective surgery. Am J Med. 1997; 102:524-30.

51. Ramasubbu K, Gurm H, Litaker D. Gender bias in clinical trials: do double standards still apply? J Womens Health Gend Based Med. 2001;10:757-64.

52. Simon V. Wanted: women in clinic trials. Science. 2005;308:1517. 